\title{
Prior Learning Assessment and Recognition (PLAR) in Canadian Universities
}

\section{CHARLES H. BÉLANGER \& JOAN MOUNT}

Laurentian University

\section{ABSTRACT}

This study suggests that Prior Learning Assessment and Recognition (PLAR) is gaining legitimacy in the university setting because of the Government/ Industry/ Labour agenda to prepare the workforce for the twenty first century; because of growing emphasis on lifelong learning characterized by mature students, part-time studies, and modular programs; because of the increasing integration of colleges and universities; and because of the prospective students' conviction that learning outside the classroom should be validated. Quality assurance and administrative issues have still to be resolved. At the same time, however, PLAR is not yet an important ingredient of university culture.

\section{RÉSUMÉ}

Cette étude suggère que la reconnaissance des acquis fait tranquillement son chemin dans le milieu universitaire parce que le gouvernement, l'industrie et le salariat ont résolu de préparer la maind'oeuvre pour le vingt-et-unième siècle; parce que l'acquisition continue du savoir prend de plus en plus d'importance comme en témoignent les programmes pour étudiants adultes, d'études à temps partiel et modulaires; parce qu'il existe une synergie croissante entre collèges et universités; parce que les étudiants potentiels ont la conviction que 
l'apprentissage hors de l'école devrait être reconnu. Reste à résoudre les questions administratives et d'assurance de la qualité. En même temps, cependant, la reconnaissance des acquis, n'est pas, à l'heure actuelle, un élément dominant de la culture universitaire.

Prior Learning Assessment and Recognition (PLAR) is based on the premise that adults acquire skills, knowledge and attitudes through a variety of formal and informal channels and that this "learning" can and should be measured against some expected outcomes and used for various purposes, including granting credit in the postsecondary setting. It is not a new concept. The American Council on Education (ACE) developed a systematic approach to evaluate the training and education provided by the various branches of the US military as far back as the early 1940's, and duplicated the same method 25 years ago to assess corporate training and education. This is not to say that PLAR is uniformly well-known and utilized across the industrialized world, but rather adds some perspective on it's evaluation within the many jurisdictions now taking the concept out of the closet and formalizing it.

Canada's experimentation with PLAR 1 has a short history, especially in the university sector. However, there seems to be an increasing interest in the idea of recognizing learning gained through work and life experience, although the extent of its actual integration within academic policy and practice is limited.

In order to shed some light on this area, a fact-finding survey of Canadian universities was conducted in 1997. This paper reports the most salient findings emerging from questions aimed at taking stock of current practice and interest in PLAR, and perceptions of its appropriateness for the university sector. These findings contribute to a growing body of knowledge related to issue identification, institutional policy, and future directions in an area that has received growing attention over the last decade.

\section{INTERNATIONAL OVERVIEW OF PLAR PRACTICES}

With the exception of the United States where Prior Learning Assessment has the longest history, international studies confirm that the interest in PLAR is recent. Parker, Leplatre and Ward (1994) observed that social change and economic renewal are at the root of this 15-yearold PLAR debate spurred by additional qualifications required, rapid 
technological change, increased occupational mobility, and a restructured organization of work. An OECD report (1994) noted that most of that organization's member countries are experimenting with a range of approaches that assume varying modes and expression. According to Barker (1995), these approaches can be clustered into three broad categories, each exemplified by particular countries:

- In Scotland and France, PLA is used to connect the occupational qualifications system with the "learning" system. That is to say, the individual undergoes PLA to determine the "mismatch between learning/skills acquired and learning/skills needed or desired. This mismatch becomes the basis for a plan to acquire those skills/knowledge, either through formal training or planned experiential learning.

- In England, Australia and New Zealand, PLA is used largely outside the established education/training system to "accredit" skills acquisition toward an occupational standard/qualification, i.e., an individual may claim to have acquired some or all of the skills on an occupational qualifications checklist.

- In Canada and the U.S., PLA has been used largely within the established education/training system to "accredit" prior learning as part of a "final" academic credential. This means that an individual may be granted some number of credits toward the total number needed to complete a degree or diploma, and not have to take courses that embody skills/knowledge that s/he has already learned."

Irrespective of the place reserved for PLAR in national systems, the body of guiding principles governing its implementation revolves around quality assurance concerns, a focus on learning, rather than how it was acquired, and an understanding that the onus to demonstrate learning rests with the candidate. Other issues center on the rigor of assessment tools, the need to make PLAR more user friendly, the need to educate the service providers (advisors, evaluators) in its use, and financial dimensions relative to institutional support and user fees. Most of these topical dimensions mirror the lead of the Council for Adult and Experiential Learning in the U.S., which developed the Ten Standards for Quality Assurance in Assessing Prior Learning (Whitaker, 1989). 
Jurisdictions share a common pool of methods to assess prior learning, and use a combination of them according to purpose and needs. Included these methods are: challenge exams for a specific course; oneon-one oral and in-person interviews; standardized tests such as those developed by ACE; performance evaluation including demonstrations, simulations, role plays; review of transcripts, licenses or certificates; and portfolio assessment. The two most recognized methods are the challenge exams, which are not particularly resource intensive for the institution, as contrasted with the portfolio approach. The latter is also labour intensive for the client, and yet is the most thorough because it forces the candidate to make explicit links between learning outcomes and learning goals.

\section{THE CANADIAN UNIVERSITY APPROACH}

Canada is said to have no national education policy, at any level, by virtue of the legislated provincial/ territorial mandate in that sector. However, national agents such as Human Resources Development Canada (HRDC), a multi-purpose federal ministry, and the Canadian Labour Force Development Board (CLFDB), a national non-profit labour force enhancement advocate, have both sponsored studies on PLAR. In the case of the former, a study conducted by Isabelle and Associates (1994) found that, apart from the work of Thomas (1989), there was little reported use of PLAR as a basis for admission and advanced standing in Canadian universities. Fifty four percent of the responding universities indicated that they did not offer any PLAR services (eg. examinations, portfolio assessment) and that very few students requested any form of assessment. Community colleges, on the other hand, were found to provide a fairly extensive menu of PLAR services, more often than not supported by orientation, counselling, and written documentation. As for CLFDB, it is fostering research and discussion papers, for example, Barker (1995), in order to try to set in motion a national PLAR strategy, in cooperation with other labour market partners. A third national player, the Canadian Association for Prior Learning Assessment (CAPLA) was founded in 1990. It has yet to find its way as a national organization and is struggling to make itself known to the university community.

Provincial initiatives are characterized by variation between and within provinces. For instance, each CEGEP in Québec administers PLA 
programs independently. By all accounts, Québec led the way in the utilization of PLA, followed by New Brunswick, British Columbia and Ontario. Although in all of these there exist provincial policies for the college sector, PLAR is still overwhelmingly a matter of institutional prerogative in universities and is generally perceived as embryonic in most. However, there seems to be more openness to the concept, as demonstrated by isolated initiatives such as the three-step study undertaken by the Council of Ontario Universities (COU) which is examining the use and implementation process of PLA in the Ontario university system, and making recommendations to impact the current structure, financing, and philosophy (COU 1996). Recently, a comprehensive program for the implementation of PLAR was put in place in British Columbia. Much like the legislated approach taken in Québec CEGEPs (late 1980s) and Ontario CAATs in 1993, the province of British Columbia program encompasses universities, university colleges, community colleges, and secondary schools. Outside of British Columbia, a handful of universities have recently produced policy statements regarding PLAR; these include the University of New Brunswick, the University of Guelph, and the University of Windsor.

Canadian universities are seen to be approaching the PLAR issue with considerable prudence in the face of powerful societal imperatives such as the changing demographics of the traditional student base into a more heterogeneous and adult group, a desire to reach a better balance between rapidly evolving market needs and labour force qualifications, and the need to optimize human and physical resources in order to minimize duplication, maximize efficiency, and facilitate mobility - not only between institutions but also between career opportunities. These factors are coupled with broad-based support for the development of a lifelong learning culture.

The explosive growth of information technology is posing a challenge to the definition of the "student" as we have experienced it since the Second World War. As described by Thomas (1998a), PLAR or "flexible evaluation" nibbles at the core of traditional paradigms such as regularity of class attendance, physical presence for set periods of time, and role in the development of curriculum. He goes on to say that students have been changing in terms of age, expectations, and experience, and that those changing cultural dimensions of the student body will have a profound impact on educational providers. 
Several authors (Fenwick, 1998; Spencer, 1998; Thomas, 1998b, 1998c) are hinting at a decline in "formal" settings by virtue of the growth of the private sector which must invest in training and development to remain competitive, and of the expanded use of PLAR which is likely to change the relationship between the formal education providing agencies with their almost exclusive power of certification and the rest of society, particularly the employment market.

As more members of industrialized societies are attending post-secondary institutions and are graduating with degrees that must be continuously updated, the concepts of "learning organizations" and "lifelong learning" are beginning to be centered not only on what students have been taught but particularly on what they have learned and are disposed to learn as members of lifelong learning entreprises and societies. Thomas (1998a) asserts that "the significance of this distinction lies in the admission that the learning can come from a great variety of sources other than that of formal instruction in a specifically designated agency of teaching" (p. 3).

\section{SURVEY DESIGN AND METHODOLOGY}

A 25-item questionnaire was sent to all Canadian institutions offering university level programmes. Wherever applicable the questionnaire was sent to the Director of Institutional Research and the Director of Continuing Education, or their equivalents. Student enrolment trends are routinely analyzed by institutional research offices, discussed with registrars, and reported to institutional principals for policy formulation. Continuing Education offices are usually identified with non-traditional, mature, and "returning" learners. Therefore, it was hypothesized that PLAR candidates were likely to investigate the potential for access and credit with Continuing Education, rather than the Registrar's Office, generally identified with the conventional 18-24 age bracket. Respondents were asked not to express their own personal beliefs or inclinations but to answer on behalf of the institution.

Each respondent was asked to identify whether his/her institution was a medical/doctoral university, a "comprehensive" university, or primarily undergraduate university. This terminology is well known in Canadian university circles since Maclean's, a national magazine, has ranked universities annually for the last seven years employing these classification labels. 
Out of the 101 questionnaires distributed, a total of 74 usable responses were received (73.3\%). Using the Statistical Package for the Social Sciences (SPSS), the data were tabulated as a pool encompassing the three types of institutions, and then separately according to classification, in order to observe institutional differences. Twenty (20) questionnaires were received from medical/doctoral universities, 17 from comprehensive universities, and 37 from primarily undergraduate universities. Since a few respondents did not answer all of the 25 questions, percentages in presented in this paper were calculated on received answers, which generally varied from 70 to 74 .

Questions dealt with three main topics: the profile that PLAR has in each institution; its appropriateness at the university level, based on institutional characteristics and mission; and anticipated directions within the institution. Likert scales were used.

\section{PLAR Profile}

Table 1 introduces the key descriptors for each of the questions asked, and presents the actual percentages obtained. There exists little variation across the three types of institutions except in the case of question \# 6. Responses to this question indicated unambiguously that medical/doctoral universities (D) do not have a Prior Learning Assessment and Recognition policy in place or in progress.

On the strength of the results, the best way to describe the PLAR profile in universities is as follows:

In a typical Canadian university, Prior Learning Assessment and Recognition is -

- a "sometimes known and spoken of" concept on campus;

- rarely part of the institutional culture;

- rarely a priority;

- more often seen as a community college issue, rather than a university one;

- more often seen as an extension of continuing education; and

- equally likely to be, or not to be, the object of "formal institutional policy."

There was unanimity among medical/doctoral universities that PLAR is not a priority, is not part of the culture, and is not often spoken of in 
Table 1

\section{PLAR Profile in Your Institution}

Rarely Sometimes Always

1. Known \& spoken of concept $\quad$ T $\quad 35 \quad 414$

\begin{tabular}{lllll} 
& D & 45 & 55 & -- \\
& C & 29 & 59 & 12 \\
& U & 32 & 46 & 22 \\
\hline 2. Part of the culture & T & 62 & 27 & 11
\end{tabular}

2. Part of the culture

D $\quad 70 \quad 30$

\begin{tabular}{lllll} 
& C & 65 & 23 & 12 \\
& U & 57 & 27 & 16 \\
\hline 3. A priority & T & 59 & 30 & 11
\end{tabular}

\begin{tabular}{|c|c|c|c|c|c|}
\hline & $\mathrm{D}$ & 65 & 35 & -- \\
\hline & & $\mathrm{C}$ & 65 & 29 & 6 \\
\hline & & $\mathrm{U}$ & 54 & 27 & 19 \\
\hline & \multirow[t]{4}{*}{ More for community colleges } & $\mathrm{T}$ & 32 & 49 & 19 \\
\hline & & $\mathrm{D}$ & 39 & 44 & 17 \\
\hline & & $\mathrm{C}$ & 18 & 59 & 23 \\
\hline & & $\mathrm{U}$ & 35 & 47 & 18 \\
\hline \multirow{4}{*}{\multicolumn{2}{|c|}{ 5. Extension of continuing }} & $T$ & 25 & 51 & 24 \\
\hline & & $\mathrm{D}$ & 21 & 42 & 37 \\
\hline & & $\mathrm{C}$ & 29 & 47 & 24 \\
\hline & & $\mathrm{U}$ & 26 & 57 & 17 \\
\hline \multirow{4}{*}{\multicolumn{2}{|c|}{ 6. Policy in place }} & $\mathrm{T}$ & 43 & 19 & 39 \\
\hline & & $\mathrm{D}$ & 50 & 6 & 44 \\
\hline & & $\mathrm{C}$ & 35 & 24 & 41 \\
\hline & & $\mathrm{U}$ & 42 & 22 & 36 \\
\hline
\end{tabular}

T: total

D: doctoral

C: comprehensive

$\mathrm{U}$ : primarily undergraduate 
day-to-day conversations. The overall pattern of responses did not differ much on these aspects among the three categories of universities

\section{PLAR Appropriateness}

This section of the questionnaire was aimed at clarifying the appropriateness of PLAR for Canadian universities. Table 2 indicates that approximately $50 \%$ of all responding universities strongly disagreed with the statement "that PLAR is NOT at all appropriate at the university level." Not one respondent strongly agreed with this statement.

These findings suggest that universities feel that the PLAR movement is being imposed on them as a consequence of strong external pressure. Sources of pressure are :

- the needs of displaced workers who once were part of a flourishing industry; [more than half of the respondents mildly $(46 \%)$ or strongly $(9 \%)$ agreed]

- the necessity of establishing and maintaining good relationships with labour and industry/business; [well over half of the respondents either mildly (45\%) or strongly (28\%) agreed]

- labour organizations pressing for the development of their members/followers; [again more than half of the respondents mildly (43\%) or strongly (12\%) agreed]

- the need to tap other sources of potential students, as traditional streams are gradually contracting;[once more the majority of respondents mildly (36\%) or strongly (23\%) agreed]

- a desire to explore the PLAR avenue, among others, in order to assist with the financial survival of the organization; [agreement was somewhat less strong, with $31 \%$ mildly in accord and 8\% strongly so]

Each type of university was asked to give its opinion on the appropriateness of PLAR for the other two types of institution, as well as for its own. Regardless of the type, data were consistent throughout in indicating that PLAR was appropriate for each type, but more so for those institutions that are primarily undergraduate (47\% strongly agreed), followed by comprehensive universities (43\% strongly agreed), and lastly medical/doctoral universities ( $32 \%$ strongly agreed).

It was thought germane to ask whether PLAR is perceived to apply most appropriately to professional studies. On the whole, the data did 


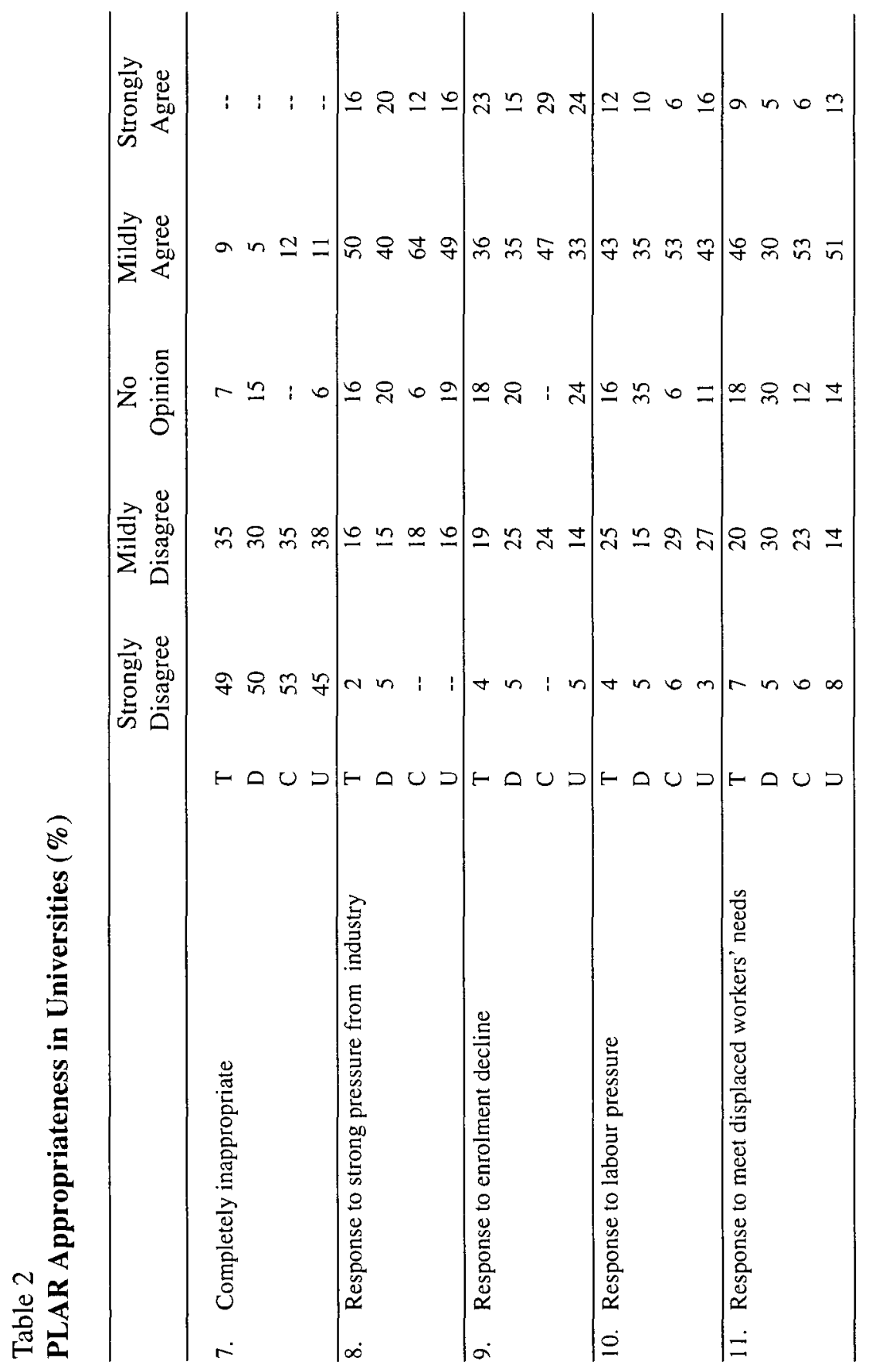

The Canadian Journal of Higher Education

Volume XXVII, No. 2, 3, 1998 





support that view, as thirty-five percent strongly disagreed and another $35 \%$ mildly disagreed.

\section{PLAR Future Directions}

Part of the questionnaire, reported in Table 3, sought to shed some light on the future use of PLAR in the university context. The majority of respondents strongly agreed (62\%) that PLAR should be employed in the accreditation of skills toward an occupational qualification such as computer technician, which is consistent with the finding that universities see PLAR more as a community college than a university issue. Prior learning accreditation as part of a "final" academic credential received somewhat less support. Nonetheless $38 \%$ of the respondents strongly concurred.

Respondents were relatively noncommittal about whether or not the implementation of PLAR would increase Canada's national and global competitiveness. They displayed more enthusiasm for the prospect that human resources in general would be enhanced by a thrust in that direction.

In spite of the fact that education is the purview of the provinces, the question was put to respondents as to whether a PLAR strategy should be province-specific or national (pan-Canadian). Interestingly enough, opinion was divided almost equally, with widely divergent responses.

What is your institution's interest in PLAR? This question was accompanied by six choices and each respondent could check as many as desired. Figure 1 exhibits the choices most often selected. Accessibility, lifelong learning, and partnering (a commitment to partnerships with industry and/ or labour) received the most support.

\section{Interpretation and Implications}

This study demonstrates both an openness of the university community towards the PLAR concept and a reluctance to implement it within its own domain. If there were a vision of a preferred future, it is perhaps that universities would much rather not have PLAR as part of the landscape. The PLAR movement challenges traditional values. If one were to take an extreme view, one could argue that it it testifies to a major paradigm shift within the university culture. We agree with Evans' observations (1994) that the principal transformations are the following: 
- recognition that all valuable learning does not take place in a classroom within specified hours;

- refocus from a full-time 18-24 year-old client base to a more mature, more selective, more heterogeneous and often parttime student population, with a requirement for different support and delivery systems;

- need for an adequate level of consensus among the academic community that PLAR services should be part of the university mandate, requiring appropriate policies, procedures, and resources.

When "extension services," the early precursors to continuing and distance education, were set up by universities some decades ago, they were seen as illegitimate but tolerated creations delivering marginal and diluted academic products. Many battles and years later, that negative perception has faded considerably but not entirely. Now, however comfortable universities may have grown with continuing and distance education, there is still no coherent body of evidence to suggest that universities are ready and willing to embrace PLAR. In a sense the barrier is a similar one, for once again the university has to come to grips with the "credit giveaway" perception and exercise caution that its reputation is not diminished in the process. The single most contentious issue which has arisen in British Columbia regarding PLAR is the debate over whether it should be transcripted in detail on student records. This question remains unresolved and is likely to spread to other provinces. It is not surprising to observe that the earliest instances of PLAR were isolated cases, and often associated with some sort of home-schooling situations in which applicants were assessed on an ad hoc basis.

A review of university calendars reveals that most universities have provisions for challenge exams. This widespread practice adds credibility to the claim of many institutions who purport to be positively disposed toward PLAR. Yet, from the clients' vantage point, challenge exams are intimidating and address the needs of a very few cases. Increasingly, taxpayers believe that educational products should be user friendly services for which they have the right (not privilege) to be considered. They call for a system that makes room for student-worker mobility between institutions and provinces, career retraining opportunities, and flexibility of learning in various circumstances and from various sources. 




The Canadian Journal of Higher Education

Volume XXVII, No. 2, 3, 1998 







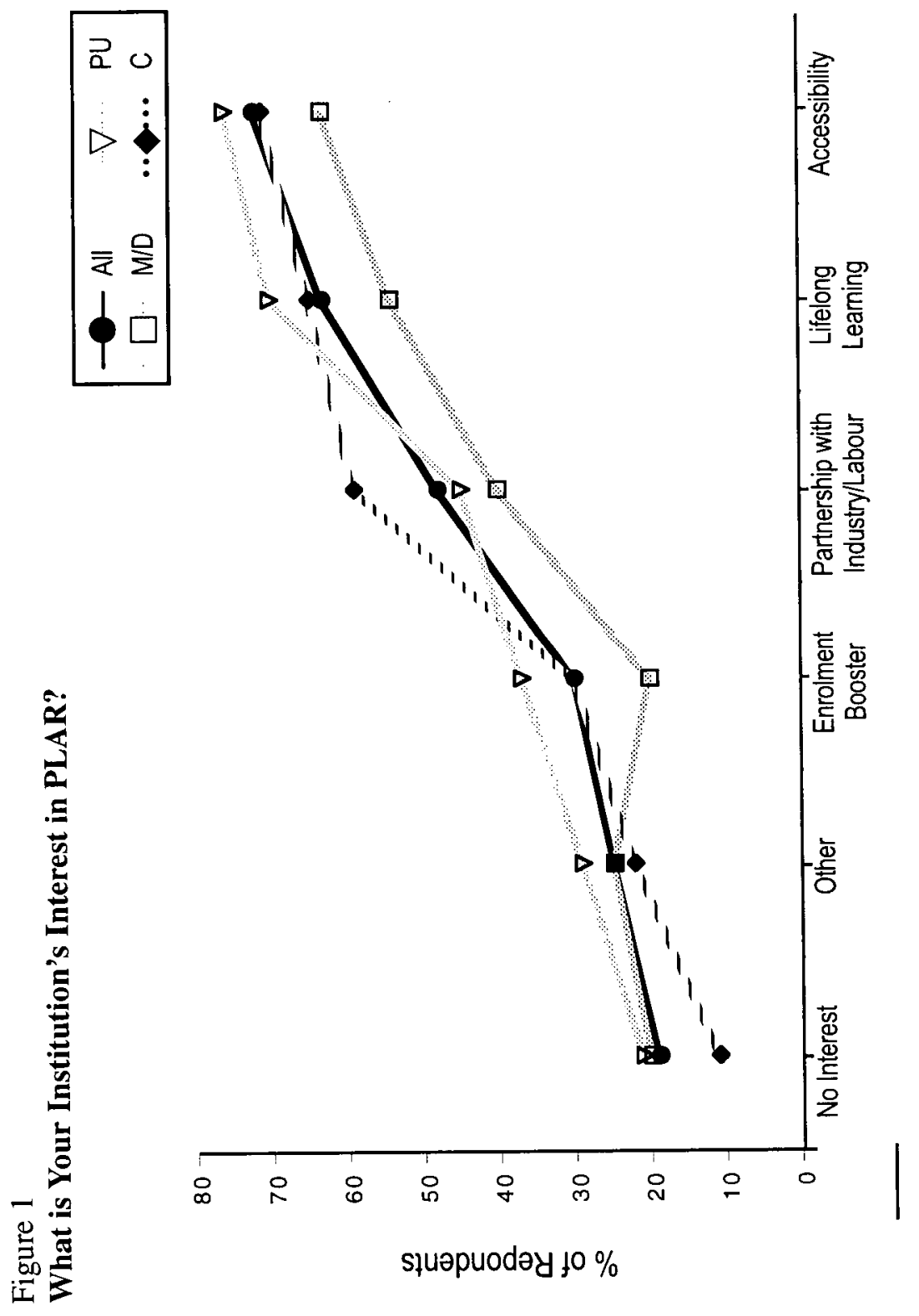

The Canadian Journal of Higher Education

Volume XXVIII, No. 2, 3, 1998 
Other jurisdictions where PLAR has a longer tradition have found that quality assurance is a serious issue, and one yet to be addressed. Educational institutions in those jurisdictions have been hard pressed to establish quality standards and consistent methods of assessment in the wake of government intervention to legislate or financially entice the introduction of PLAR into the system.

Consider the Ontario college system which was encouraged, through inducements by the provincial government, to adopt PLAR into its curriculum in 1993. When university policy makers reflect on this example, they may well figure that the agenda in store for them will be similar. It is noteworthy that though universities affirm that the application of PLAR should NOT be confined to professional study areas, marked inroads have been made in fields such as the Nurse Practitioner programme which entails a training component. From here the applications will no doubt expand, and if one follows the trend of this survey, primarily undergraduate universities would be expected to lead the way. At the same time, comprehensive and medical/doctoral universities are likely to follow within hailing distance in order not to be labeled as reactionary, elitist, or inaccessible. On the other hand, undergraduate universities are likely to move with caution for fear of eroding the value of the university degree. If British Columbia and Ontario colleges are a reflection of likely demand, universities should not expect a deluge of PLAR applicants, since only minimal numbers have been recorded in these two provinces since the PLAR inception (Thomas, 1998a).

To the extent that experiences with PLAR within the community college system can assist in successful implementation within universities, a number of important elements are worth considering. The Quebec college system, for instance, has found that PLAR must be integrated into the institution's administrative process; that assessment tools must be rigorous; and financial support and additional resources must be made available. Further, the process must take into consideration professional development needs of faculty and staff, in order to make course formulation amenable to learning outcome measures and to acquaint those who will evaluate PLAR candidates with the best practices. The British Columbia system has determined that student fees for PLAR services should be geared to the amount of credit being requested, as opposed to the amount of credit that is awarded. The Province of Ontario is currently moving to factor PLAR funding into 
the operating grants formula for colleges on the basis of an agreed upon ratio. The Council of Ontario Universities may undertake to negotiate a similar arrangement with the Province if it sees the need.

Beyond the college experience and the popularity associated with the PLAR phenomenon, universities are the ones who must ultimately formulate their position within their own accountability norms. Further, Canadian universities are very protective of their autonomy from the government and are not about to relinquish it. They have to decide to what extent, as universities, they are mandated on the one hand to educate, and on the other hand, to train. Traditionally, there has been a line in the sand, mandating colleges to train and universities to educate. This distinction in roles is increasingly challenged by societal agents and learners themselves, aware of the necessity to meet the needs of a world-class workforce prepared for the knowledge-based global economy. As reported by Farris (1994) after making a study of training reform in five countries, the new demands require partnerships, responsiveness, flexibility, relevance, and quality - all characteristics that have been debated in university circles for many years. It is up to universities to define the bridging role they wish to play in the triangle composed of the learner's acquired skills and knowledge (PLAR), the skills and knowledge needed (occupational standards), and how the skills and knowledge gap can be filled (formal and experiential learning). Besides the relevant social and political considerations, there exist important pedagogical and scholarly issues such as: Are the skills and information that are being recognized by PLAR different in kind from university learning and to what extent does the granting of equivalence raise some concern? Or is it possible that the "special nature" of university coursework amounts to a self-serving assumption that does not necessarily stand up to serious and measured scrutiny? Answers to those questions require considerable reflection and forethought in order to serve everyone's best interests, particularly in the long run.

\section{CONCLUSION}

The Prior Learning Assessment and Recognition movement casts learning in terms of outcomes which relate to goals. This perspective forces the learner to be more focused, and also encourages more rigor in course formulation and delivery on the part of the instructor/ learning facilitator. Further, the emphasis is on avoiding redundant schooling, with consequent conservation of scarce resources both for the learner 
and the institution. Needless to say, there are administrative costs associated with PLAR but clearly there are savings implied by streamlining unnecessary classroom time.

Prior Learning Assessment and Recognition is "learner-centred" in that it validates learning regardless of the vehicle whereby it is attained. This perspective has practical payoffs. From the standpoint of the institution, a learner centred orientation manifested through PLAR can serve as a marketable benefit to the growing pool of adult learners. Institutions are already adapting some graduate programs to the needs of the employed adult. It is not incongruent with present practice to incorporate PLAR into the mosaic of features to accommodate the adult learner.

Yet quality assurance issues loom large. Institutions are wary, with good reason, of any step that might be perceived to diminish the quality of their degrees. Given this understanding, it is logical to suggest that PLAR will first appear in degree programs where there are standardized professional accreditation examinations and/ or where the use of PLAR is a network or consortium phenomenon rather than lodged in a single institution. Otherwise it is most likely to be accepted incrementally into the university system via linkages with community colleges. Where it occurs and the extent to which it occurs may well, in the short run, be largely a function of articulation arrangements which legitimize PLAR within degrees, with it normally being recognized within the antecedent college segment.

This study does not, however, indicate whether the respondents were agreeing that there were in fact some powerful external considerations pushing us toward PLAR or whether they were in fact agreeing that those were legitimate forces, with PLAR a legitimate response. The former does not necessarily imply endorsement - except strategically and perhaps cynically - of PLAR. The latter suggests an academic as well as public policy legitimacy.

Mature learners may bring to the formal educational arena knowledge and skills that deserve to be recognized. The black box of post-secondary courses and credits must become judiciously porous. PLAR is not a fad; it is a cogent response to the changing learner population. If universities fail to respond, it is a sure bet that alternative educational providers will seize the opportunity. 


\section{Notes}

1 APL (Accreditation of Prior Learning), RPL (Recognition of Prior Learning), AEL (Assessment of Experiential Learning), and CPL (Credit for Prior Learning) are virtually synonymous.

\section{References}

Barker, K. (1995). Prior Learning Assessment: Issues and opportunities for the $C L F D B$. Ottawa, ON: Canadian Labour Force Development Board.

Council of Ontario Universities (1996). Prior Learning Assessment: Issues and opportunities for Ontario's universities. Toronto, ON: COU.

Evans, S. (1994). Discussion paper on Prior Learning Assessment. Paper presented to the National Symposium on Prior Learning Assessment. St. John's,NF: Cabot College of Applied Arts, Technology and Continuing Education.

Farris, R. (1994). Major reforms in training systems in five countries: A review of reforms in Scotland, England and Wales, Australia, New Zealand, and the United States. Victoria, BC: British Columbia Ministry of Skills, Training, and Labour.

Fenwick, T. (1998). Questioning the concept of the learning organization. In S. Scott, B. Spencer, \& A. Thomas (Eds), Learning for life: Canadian readings in adult education (pp. 40-152). Toronto, ON: Thompson Education Publishing.

Isabelle, R. (1994). Survey of Prior Learning Assessment in Canada. Report prepared for Human Resources Development Canada. Montreal, PQ: Robert Isabelle and Associates.

OECD (1994). Assessment and recognition of skills and competencies, provisional report. Paris: Directorate for Education, Employment Labour and Social Affairs.

Parker, H., Leplatre, F., \& Ward, C. (1994). Identification and accreditation of skills and knowledge acquired through life and work experience: Comparative reports of practice in France and the $U K$. Mimeographed.

Spencer, B. (1998). Distance education and the virtual classroom. In S. Scott, B. Spencer, \& A. Thomas (Eds), Learning for life: Canadian readings in adult education (pp. 343-363). Toronto, ON: Thompson Education Publishing.

Thomas, A. (1989). The utilization of Prior Learning Assessment as a basis for admission and the establishment of advanced standing in education in Canada. Toronto. ON: Ontario Institute for Studies in Education. 
Thomas, A. (1992). Utilization of Prior Learning Assessment in Canada. Canadian Journal of University Continuing Education, 17(1), pp. 7-26.

Thomas, A. (1998a). The challenge of prior learning assessment to universities in Ontario. Aide Memoire presented ot the Council of Ontario Universities. Toronto, ON.

Thomas, A. (1998b). Learning our way out. In S. Scott, B. Spencer, \& A. Thomas (Eds), Learning for life: Canadian readings in adult education (pp. 354-364). Toronto, ON: Thompson Education Publishing.

Thomas, A. (1998c). The tolerable contradictions of prior learning assessment. In S. Scott, B. Spencer, \& A. Thomas (Eds), Learning for life: Canadian readings in adult education (pp. 330-342). Toronto, ON: Thompson Education Publishing.

Whitaker, U. (1989). Assessing learning: Standards, principles and procedures. Chicago, IL: Council for Adult and Experiential Learning. 